\title{
A saúde no Brasil e em Portugal na atualidade: o desafio de concretizar direitos ${ }^{*}$
}

\author{
Health in Brazil and in Portugal in the present: \\ the challenge of achieving rights
}

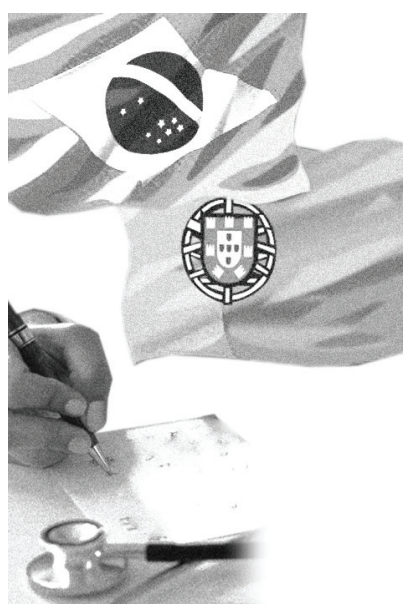

Maria Inês Souza Bravo*

Resumo: O artigo procura analisar a política de saúde no Brasil e em Portugal desde a garantia da universalidade, no processo de redemocratização dos dois países, até os dias atuais. Ressalta as modificações ocorridas após os anos 1990 nos dois países, com destaque para a gestão dos serviços de saúde com a criação de "novos" modelos gerenciais. Aborda-se também, de forma sucinta, a temática do aborto como questão de saúde pública, pois é um tema em debate na atualidade em ambos os países, embora não seja objeto deste texto.

Palavras-chave: Política de saúde. Alterações no sistema de saúde. Gestão da saúde.

\begin{abstract}
The article analyses both the Brazilian and the Portuguese health policy from the guarantee of universality in the two-country process of democratization to the current days. The changes in the two countries after the nineties will be highlighted, with emphasis on the management of health services with the creation of "new" management models. The article also discusses the problem of abortion as a public health issue briefly because it is a topic on debate in both countries nowadays, although that is not the subject of this article.
\end{abstract}

Keywords: Health policy. Changes in health care management. Health management.

* Texto fruto de estágio pós-doutoral realizado em Portugal, no período de agosto a outubro de 2007, financiado pela Coordenação de Aperfeiçoamento de Pessoal de Nível Superior (Capes). É uma versão ampliada do trabalho apresentado na $19^{\mathrm{a}}$ Conferência Mundial de Serviço Social, realizada em Salvador/Brasil, em 2008.

** Assistente social, doutora em Serviço Social pela PUC-SP, pós-doutorado pela UFRJ, professora aposentada da UFRJ, professora adjunta da Faculdade de Serviço Social da Universidade do Estado do Rio de Janeiro - Uerj; Procientista da Uerj e coordenadora do Projeto Políticas Públicas de Saúde: o Potencial dos Conselhos do Rio de Janeiro, financiado pelo CNPq e Uerj — Rio de Janeiro/RJ, Brasil. E-mail: mibravo@uol.com.br. 


\section{Apresentação}

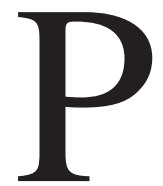

retende-se apresentar as principais questões debatidas com relação à política de saúde nos dois países desde meados dos anos 1970. Brasil e Portugal vão garantir a universalidade da saúde em momentos diferentes, mas ambos no processo de redemocratização vivenciado pelos dois países e contida nas Constituições aprovadas pelo Estado democrático e de direito.

A reestruturação do sistema de saúde em Portugal decorre da Constituição democrática de 1976 - convocada após o processo revolucionário de 1974, conhecido como Revolução dos Cravos, que cria o Serviço Nacional de Saúde (SNS) que garante a gratuidade do serviço.

No Brasil, o Sistema Único de Saúde (SUS) está contido na Constituição Cidadã de 1988, promulgada durante o processo de transição democrática ocorrido no país que tem como princípios: universalidade, descentralização, integralidade e participação popular. Esta conquista foi resultado do movimento sanitário articulado aos demais movimentos sociais que se mobilizam desde meados dos anos 1970 e formula o projeto de Reforma Sanitária ${ }^{1}$ que tem como eixo central as reformas sociais, a determinação social do processo saúde-doença e a defesa da saúde como direito de todos e dever do Estado. ${ }^{2}$

As modificações e alterações ao Projeto de Saúde democrática começam a ocorrer nos dois países a partir dos anos 1990, com a influência das agências internacionais que indicam a necessidade de contrarreforma do Estado e a política de ajuste.

Em Portugal, já há uma alteração no final dos anos 1980, com a reforma constitucional de 1989 que tem por objetivo a cobrança de "taxas moderadoras" aos serviços de saúde, alterando na Constituição para tendencialmente gratuito (Arnaut, 2005). A política de saúde em Portugal, segundo o relatório da primavera de 2002, do observatório português dos sistemas de saúde, pode ser analisada em duas grandes fases (Simões, 2004): 1970 a 1985 e a partir de 1985. A primeira é

1. O Projeto de Reforma Sanitária brasileiro é objeto de diversos estudos. Para maior aprofundamento vide: Paim (2008), Bravo (1996), Teixeira (1989).

2. A análise do processo saúde-doença a partir de seus determinantes sociais é uma questão fundamental, pois relaciona saúde e trabalho e teve como influência teórica o marxismo. Essa concepção na atualidade está sendo reduzida a fatores sociais que promovem a saúde ou causam as doenças, retomando o pressuposto positivista da epidemiologia tradicional. 
denominada Sistema Nacional de Saúde e a sua expansão, tendo como marco a Constituição da República de 1976, que estabeleceu que o direito à proteção da saúde é realizado pela criação de um serviço nacional de saúde universal, geral e gratuito. A segunda predominou a partir de 1985, tendo como agenda mudar a fronteira entre público e privado, favorecendo o setor privado.

Na década de 1990, nos dois países assiste-se a sucessivas alterações no sistema de saúde, com o argumento de falta de recursos por parte do Estado.

Em Portugal, as principais alterações no Sistema Nacional de Saúde são: responsabilidade conjunta pela saúde, ou seja, dos cidadãos, da sociedade e do Estado (antes era principalmente do Estado); criação de seguro-saúde; estabelecimento de taxas moderadoras a serem cobradas pelo SNS e a flexibilização da gestão dos serviços podendo ser desenvolvida por meio de convênios e cooperativas médicas através da prestação de serviços privados no setor público (Carreira, 1996; Abreu, 2004).

No Brasil, as contrarreformas na saúde nos anos 1990 foram: contenção dos gastos com racionalização da oferta por meio de políticas focais através do pacote básico para a saúde; estímulo ao seguro privado; descentralização dos serviços em nível local; desfinanciamento da saúde.

Dois temas têm sido centrais na atualidade no debate relativo à saúde, nos dois países: o aborto e a reestruturação do sistema por meio de "novos" modelos de gerenciamento. $\mathrm{O}$ trabalho pretende ressaltar o segundo tema e apenas pontuar o primeiro em face da intencionalidade do texto, conforme já referido no resumo. ${ }^{3}$

\section{A questão do aborto}

O debate sobre o aborto em Portugal tem uma trajetória histórica mais densa do que no Brasil. Desde 1940, Cunhal (1997) já alertava para o risco dos abortos clandestinos. Na conjuntura democrática inaugurada em 1974, o debate sobre a descriminalização voltou à cena. Em 1998, foi debatido na sessão da Assembleia da República, e aprovada a realização de um plebiscito cujo resultado das urnas foi contrário. Quase dez anos depois, a temática volta a ser debatida e é realizado um novo plebiscito em 2007, apontando para a legalização da interrupção voluntária da gravidez.

3. Esses dois temas foram também destacados por Matos (2009). 
A questão do aborto em Portugal conseguiu aglutinar forças sociais envolvendo os partidos de esquerda, os movimentos sociais e foi objeto de discussão desde a redemocratização do país. Como já explicitado, foram realizados dois plebiscitos: um em 1998, cujo resultado das urnas foi desfavorável, e outro quase dez anos depois, em 2007, em que a legalização da interrupção voluntária da gravidez foi aprovada. Foi necessária, entretanto, a elaboração de uma lei moderada sobre o assunto, pois o debate ainda permanece. A lei prevê a constituição, nos serviços de saúde, de uma equipe com profissionais da área social e psicológica para aconselhamento das mulheres que desejam interromper a gravidez.

No Brasil, a questão tem sido colocada prioritariamente pelo movimento feminista, e somente em 2007 foi levantada pelo ministro da Saúde como questão de saúde pública, sendo respaldada por algumas entidades do movimento sanitário e pelo movimento feminista. A reação da Igreja, entretanto, foi muito polêmica quanto à exposição do ministro e, para fortalecê-la, houve coincidência com a visita do papa ao país. A descriminalização do aborto foi debatida na $13^{a}$ Conferência Nacional de Saúde, realizada em novembro de 2007, mas perdeu na plenária final, com grande resistência ao debate. Nas conferências anteriores também esta questão não conseguiu ser aprovada.

No Brasil, este debate não está disseminado entre os partidos políticos, os sindicatos e os movimentos sociais. Há uma reação muito grande à proposta que precisa ser ampliada, aprofundada para ganhar adesões e enfrentar os preconceitos.

A influência da Igreja é muito forte nos movimentos de saúde e denota valores cristalizados e uma negação ao debate do tema. A Pastoral da Criança tem congregado vários militantes para que sejam contrários à proposta.

Esta é uma luta que precisa congregar vários movimentos sociais articulados e ser amplamente discutida com a sociedade, constituindo-se num desafio a ser enfrentado pelos diversos sujeitos sociais.

A seguir será abordada a questão da gestão dos serviços nos dois países, temática central do artigo.

\section{A gestão dos serviços de saúde em Portugal e no Brasil}

Esta temática torna-se central nos dois países a partir dos anos 1990, apesar de ter sido apontada nos países centrais desde meados da década de 1970. 
O debate acerca das reformas do Estado, ou contrarreformas, como afirmam alguns autores, tem relação com o fenômeno da globalização ${ }^{4}$ e/ou mundialização, ${ }^{5}$ quando se observa um movimento de acelerada expansão do capital financeiro e da universalização de mercados que ocorre a partir dos anos 1970, em decorrência da crise do capitalismo monopolista (Bravo, 2007).

Harvey (1993) assinala a exaustão do padrão capitalista monopolista fundado num regime de acumulação (e seu modo de regulação) "rígido" designado como "fordista-keynesiano" para um outro regime de acumulação "flexível" que implica necessariamente um correspondente modo de regulação.

Essas transformações vêm acompanhadas de profundas mudanças na esfera do Estado, consubstanciadas na reforma exigida pela "política de ajuste", recomendada pelo consenso de Washington (Fiori, 1993).

O grande capital rompe com o "pacto" que suportava o Welfare State, com a retirada das coberturas sociais públicas, com cortes nos direitos sociais. O processo de ajuste visa diminuir o ônus do capital no esquema geral de reprodução da força de trabalho. Configura-se um Estado mínimo para os trabalhadores e máximo para o capital (Netto, 1993).

O poder do capital financeiro é defendido pelo Fundo Monetário Internacional (FMI), pelo Banco Mundial (BM) e pela Organização Mundial do Comércio (OMC), que representando os interesses dos Estados mais poderosos pressionam os demais para adotarem política de liberalização e privatização impondo reformas sociais, econômicas e políticas.

Essas propostas têm influenciado as políticas sociais de diversas formas, com corte nos gastos sociais, retração significativa do setor público por meio de processos de privatização, introdução de mecanismos típicos de mercado no setor público.

4. A discussão acerca dos significados e características do fenômeno de globalização fogem ao âmbito deste estudo. Para Fiori (1995), o conceito procura dar conta de uma nova formatação capitalista gerada nas últimas décadas pelo acelerado processo de acumulação e internacionalização de capitais. Esse processo teria se dado em várias dimensões, culminando numa reorganização espacial da atividade econômica e na re-hierarquização dos seus centros decisórios. Dessa forma, para além da dimensão econômica, o autor enfatiza os aspectos políticos e ideológicos envolvidos nesse processo, que seriam resultado também das decisões políticas tomadas pelos governos, sob a hegemonia liberal-conservadora. $\mathrm{O}$ autor destaca ainda a heterogeneidade entre países quanto à posição de poder que ocupam na nova ordem internacional e às diferentes respostas desses países ao novo contexto.

5. Chesnais (1996) explicita que a fase de mundialização representa um novo estilo de acumulação, com predomínio financeiro e rentista, e ocorre pelas novas formas de centralização de gigantescos capitais financeiros. Para o autor, esta fase foi antecipada pelo imperialismo e pelo período fordista. 
No que se refere à administração pública, as "reformas" têm sido orientadas por medidas que usam a redução dos gastos e o aumento da eficiência dos equipamentos públicos, o que é um paradoxo, pois os cortes excessivos vão prejudicar o desempenho da administração a longo prazo (Kettl, 1996).

Outra perspectiva tem sido o fortalecimento do gerencialismo ${ }^{6}$ como fio condutor das agendas das reformas em diversos países (Kettl, 1996; Abrucio, 1998), que tem como características: ênfase na flexibilização da administração e das modalidades de contratação de funcionários; diminuição de mecanismos de contratualização entre governo e instituições públicas (Bravo, 2007).

A literatura recente aponta que vem ocorrendo uma modificação no debate acerca da reforma do Estado nos anos 1990. Na década de 1980, predominou uma agenda minimalista em face dos imperativos do ajuste estrutural macroeconômico. Nos anos 1990, a ênfase se deslocou para as reformas institucionais, com vistas ao aumento da capacidade do Estado para viabilizar o sucesso das medidas de ajuste e atenuar suas consequências sociais. Nesse período, ganham centralidade os conceitos de governança e governabilidade ${ }^{7}$ (Machado, 1999).

Haggard (1997), ao discutir as tendências das reformas na América Latina, afirma que nos anos 1980 predominaram, na maioria dos países, as medidas de ajuste macroeconômico e de balanças de pagamento, sendo que as medidas institucionais se restringiam às privatizações em algumas áreas. Na década de 1990, entretanto, o debate passa a enfocar as mudanças institucionais necessárias para a implementação das reformas. ${ }^{8}$

As propostas de mudanças relacionadas ao papel do Estado vão repercutir efetivamente na política de saúde. A partir dos anos 1980, observa-se uma tendên-

6. O termo original é managerialism, que seria uma corrente original dos EUA — mas nunca implementada radicalmente naquele país - e norteadora da reforma administrativa no Reino Unido na década de 1880 (Kettl, 1996; Abrucio, 1998; Macedo e Alves, 1997). Abrucio (1998) aponta uma "evolução" das correntes do gerencialismo ao longo dos anos 1980 e 1990, com tendência de retomada de princípios como transparência, equidade e justiça social. As três correntes discutidas pelo autor são: o "gerencialismo puro"; o "consumerism"; e a "public service orientation".

7. Uma análise das origens e significados da categoria governabilidade pode ser vista nos trabalhos de Melo (1995) e de Fiori (1995). Mattos (1996) também aborda a questão da governabilidade e traça uma descrição detalhada do surgimento do conceito de "good governance" no interior do Banco Mundial. Diniz (1997) discute as duas categorias como elementos auxiliares no debate acerca da construção de um novo paradigma de reforma do Estado.

8. O termo reforma está sendo empregado em face de sua utilização por diversos autores. Entretanto, considera-se que a denominação mais adequada é "contrarreforma", pois as mesmas vão na direção de supressão de direitos, enquanto as reformas têm sua origem nas lutas sociais e progressistas. 
cia de "reformas" no setor saúde em vários países, em geral relacionadas à reformulação dos sistemas de proteção social.

Almeida (1996), ao analisar as reformas europeias na década de 1980, aponta quatro linhas norteadoras: separação entre financiamento e previsão de serviços, com redefinição do papel do Estado; utilização de incentivo e subsídios, visando à reestruturação do mix público-privado; racionalização da assistência médica, com redirecionamento dos gastos para práticas extra-hospitalares; introdução de mecanismos de competição nos sistemas de saúde. A mesma autora ressalta que, nos anos 1990, os modelos reformadores tentam suavizar o discurso ideológico exacerbado da década de 1980, partindo da crítica às propostas neoliberais sem, entretanto, significar um retorno às premissas do Estado de Bem-Estar Social.

A agenda pública na década de 1990 tem como questão central reconstruir a capacidade do Estado, reestruturando-o simultaneamente (Fiori, 1993). Cinco temas têm influenciado a agenda de reformas internacionais para a América Latina, desenvolvidos pelo Banco Mundial e outras organizações internacionais (Kaufman, 1995, p. 2): a centralização e insulamento político do controle da política macroeconômica; a descentralização e privatização das burocracias; a introdução da competição entre provedores de bens e serviços como forma de aumentar a eficiência; a delegação de funções regulatórias a agências independentes encarregadas de monitorar os prestadores de serviços; a criação de um quadro restritivo de funcionários públicos "essenciais", mais capazes, com considerável poder operacional, que seriam avaliados segundo padrões de desempenho.

A partir dessas considerações gerais, serão especificadas as principais questões com relação à saúde nos dois países analisados.

Rosa (2006) afirma que um dos direitos dos portugueses mais atacados pelos grandes grupos econômicos na atualidade é o direito à saúde tendencialmente gratuito, garantido pela Constituição da República. O autor ressalta que a reforma do início da década de 1990 já havia inscrito a possibilidade da gestão dos serviços de saúde para o setor privado, por meio de contrato de gestão. Entretanto, salienta que é em 2002, no governo PSD/PP (Partido Social Democrata/Partido Popular) que é realizada uma "alteração cirúrgica" na Lei n. 48/90 e a promulgação de vários decretos-leis tendo por objetivo a privatização do Serviço Nacional de Saúde. Cabe destacar, entre eles, a transformação dos hospitais públicos em hospitais S.A.; a Lei de Parcerias Público-Privados (PPP), que permite a entrega da exploração e a construção dos hospitais ao setor privado; a revisão do contrato 
de trabalho dos profissionais de saúde e a criação de um decreto-lei que possibilitava a entrega da gestão dos centros de saúde, ou parte deste, a entidades públicas ou privadas. O autor considera que o governo tinha a intenção de introduzir mudanças nas "taxas moderadoras", mas que não foram em frente devido à mudança de governo.

O atual governo, do primeiro-ministro Sócrates, do Partido Socialista (PS), não alterou a política de saúde do governo anterior, mas deu continuidade às suas proposições. Rosa (2006, p. 256-257) chama a atenção para os seguintes aspectos: ao revogar o decreto-lei que possibilitava a entrega dos centros de saúde ao setor privado, o atual governo não revogou a disposição da Lei de Bases da Saúde que também permite essa possibilidade. O governo não se propôs a acabar com o modelo de gestão dos hospitais por meio de parceria público-privada, mas apenas revê-los, e viabiliza um expressivo plano de investimento financeiro para as parcerias público-privadas na saúde nos próximos anos, segundo o orçamento do Estado de 2006. Outra medida ressaltada pelo autor é a transformação dos Hospitais S.A. em Entidades Públicas Empresarias (EPE), que mantêm a possibilidade de transferência da gestão destes para o setor privado.

Rosa (2006, p. 259-260) destaca ainda as seguintes metas do próprio governo, contidas no relatório do orçamento do Estado: alterar o regime de compartimentalização, entre usuário e Estado, dos custos com medicamentos, visando à redução do gasto estatal; empresarializar os hospitais e centros de saúde; continuar a parceria público-privada abrangendo outros hospitais; identificar e avaliar o patrimônio do setor saúde com vistas a possíveis rentabilizações.

A reforma da saúde do atual governo ganhou espaço na mídia principalmente com relação a duas medidas: o fechamento de vários serviços de emergência e o aumento dos valores e da extensão para a prestação de outros serviços de saúde das taxas moderadoras. Esses dois temas, apesar de serem apenas expressões de uma ampla reforma com relação à saúde, expressam que a política estatal da saúde tem obtido manchetes nos jornais (Matos, 2009).

Há também uma reação dos movimentos sociais às mudanças no Sistema Nacional de Saúde. Várias manifestações políticas ocorreram em diversas cidades de Portugal contrárias a essas mudanças, embora sem a cobertura da mídia. A maior expressão da rebeldia dos portugueses ocorreu no dia 25 de abril de 2007, em comemoração da Revolução dos Cravos. Nessa manifestação, a maior ala era a de 
associações de moradores, e a maioria dos cartazes e faixas se referia contra as reformas do Serviço Nacional de Saúde. ${ }^{9}$ Os dois partidos de oposição, o Partido Comunista Português (PCP) e o Bloco de Esquerda, também têm se manifestado contrários às mudanças no Sistema Nacional de Saúde.

No Brasil, o projeto da reforma sanitária começa a ser questionado no início dos anos 1990 e, na segunda metade dessa década, consolida-se o projeto de saúde articulado ao mercado ou privatista. Este último é pautado na política de ajuste, que tem como tendência a contenção dos gastos com a racionalização da oferta e a descentralização com isenção de responsabilidade do poder central. Ao Estado cabe garantir um mínimo aos que não podem pagar, ficando para o setor privado o atendimento aos cidadãos consumidores. Como principais características destacam-se: o caráter focalizado para atender às populações vulneráveis, a privatização dos serviços e o questionamento da universalidade do acesso.

No primeiro governo de Fernando Henrique Cardoso (FHC) é apresentada a proposta das Organizações Sociais (OS), explicitadas no Plano Diretor da Reforma do Aparelho de Estado. As OS foram concebidas como instrumento para viabilizar as políticas públicas, podendo contratar funcionários sem concurso público, adquirir bens e serviços sem licitações e não prestar contas à administração pública. Em 1999, foram instituídas na esfera federal as Organizações da Sociedade Civil de Interesse Público (Oscip), que propõem a qualificação de pessoas jurídicas de direito privado, sem fins lucrativos, e institui o termo parceria.

A primeira eleição de Luiz Inácio Lula da Silva significou um marco político na história do país, pois foi a primeira vez que se elegeu "um representante da classe operária brasileira com forte experiência de organização política" (Braz, 2004, p. 49). A consagração eleitoral foi resultado da reação da população contra o projeto neoliberal implantado nos anos 1990, vencendo o projeto que não representava, em sua origem, os interesses hegemônicos das classes dominantes. Apesar das dificuldades do cenário internacional, com a pressão dos mercados e do capitalismo financeiro, acreditava-se que no Brasil estaria se inaugurando um novo

9. Segundo Matos (2009), além destas manifestações, deve-se ressaltar os atos do dia do trabalhador $\left(1^{\circ}\right.$ de maio) e a greve geral de 30 de maio, convocada pela Central Geral dos Trabalhadores Portugueses (CGTP), apesar de não ter conseguido paralisar todos os serviços. Em 5 de julho de 2007 essa Central teve papel decisivo no ato contrário à política de emprego e às políticas sociais ocorrido em Guimarães, durante a reunião dos ministros do emprego da União Europeia, que congregou aproximadamente 25 mil manifestantes. 
momento histórico em que se enfrentaria as políticas de ajuste. Não eram esperavas transformações profundas, em face dos acordos ocorridos, mas havia expectativas com relação às políticas sociais e à participação social.

A política de saúde vem sofrendo os impactos da política macroeconômica, e as questões centrais não estão sendo enfrentadas, como: a universalização das ações; o financiamento efetivo; a política de gestão do trabalho e educação na saúde e a política nacional de medicamentos.

No segundo governo Lula, é escolhido para ministro da Saúde um ator que participou da formulação do Projeto de Reforma Sanitária, nos anos 1980.

$\mathrm{O}$ atual ministro tem levantado para o debate questões polêmicas, como a legalização do aborto, considerado como problema de saúde pública; ${ }^{10}$ a ampliação das restrições à publicidade de bebidas alcoólicas e a necessidade de fiscalizar as farmácias. Tem tomado também algumas medidas, entre as quais a de maior impacto foi a quebra de patente do medicamento Efavirenz (Stocrin), da Merk Sharp \& Dohme, elogiada amplamente pelas entidades de combate à Aids (revista Época, 14 de maio de 2007).

O ministro, entretanto, não tem enfatizado algumas questões centrais ao ideário reformista construído desde meados dos anos 1970, como a concepção de seguridade social, a política de recursos humanos e/ou gestão do trabalho e educação na saúde e saúde do trabalhador. Apresenta, por outro lado, proposições que são contrárias ao projeto, como a adoção de um novo modelo jurídico-institucional para a rede pública de hospitais, ou seja, a criação de fundações estatais.

A proposição mais preocupante do atual ministro é a criação das fundações estatais, cujo debate está mais avançado na saúde,${ }^{11}$ mas pretende atingir todas as áreas que não sejam exclusivas de Estado, como: saúde, educação, ciência e tecno-

10. Neste debate, entretanto, não fez uma articulação efetiva com os movimentos feministas,.

11. Na saúde este debate inicia-se com a crise da saúde no Rio de Janeiro e teve impulso com a criação e elaboração, pela equipe de trabalho constituída pelos Ministérios do Planejamento e Saúde com a participação de professores da Escola Nacional de Saúde Pública Sergio Arouca (Ensp/Fiocruz), Instituto de Direito Sanitário Aplicado (Idisa), Sunfeld Advocacia/SP, do documento que foi apresentado, inicialmente, no Congresso da Abrasco, em 2006, com o título "Gestão em saúde: novos modelos de gestão para os institutos e hospitais do Ministério da Saúde" e, posteriormente, teve revisão no título para fundações estatais. Atualmente, há uma articulação entre os estados da Bahia, Rio de Janeiro, Espírito Santo e Sergipe para a adoção deste modelo, bem como para os hospitais federais do Rio de Janeiro. 
logia, cultura, meio ambiente, desporto, previdência complementar, assistência social, entre outras..$^{12}$

Algumas questões podem ser levantadas com relação a esta proposta: as fundações serão regidas pelo direito privado; têm seu marco na "contrarreforma" do Estado de Bresser Pereira/FHC; a contratação de pessoal é por CLT, acabando com o RJU (Regime Jurídico Único); não enfatiza o controle social, pois não prevê os conselhos gestores de unidade e sim conselhos curadores; não leva em consideração a luta por plano de cargo, carreira e salário dos trabalhadores de saúde; não obedece às proposições da $3^{\text {a }}$ Conferência Nacional de Gestão do Trabalho e Educação na Saúde, realizada em 2006; fragiliza os trabalhadores por meio da criação de planos de cargo, carreira e salário por fundação.

Os movimentos sociais têm reagido a essa proposição. Em 2007, o Conselho Nacional de Saúde se posicionou contrário a essa proposta. Nesse ano, foram realizadas conferências estaduais em todos os estados brasileiros e a $13^{\mathrm{a}}$ Conferência Nacional de Saúde - o maior evento envolvendo a participação social no país. Em todas essas conferências a proposta de criação das Fundações foi rejeitada.

No estado do Rio de Janeiro, a saúde já é objeto de lei regulamentar: 24 unidades hospitalares e institutos integrariam a estrutura de três fundações gestionárias do serviço público de saúde. Entre o Estado, devedor de um serviço público essencial, e o usuário, detentor de um direito fundamental, surge um intermediário, um gestor, as fundações privadas instituídas pelo poder público.

Um fórum permanente, composto por centrais sindicais, sindicatos, representantes de conselhos estaduais e municipais de saúde, projetos de pesquisa universitária e outras entidades, foi o caminho de unidade encontrado pelo movimento social no Rio de Janeiro com a criação do Fórum em Defesa do Serviço Público e contra as Fundações. Instalou-se para intervir no processo de tramitação da lei e se manteve, buscando abrir para outros movimentos, especialmente nas áreas futuramente afetadas pelo projeto de fundações. ${ }^{13}$ Nos demais estados brasileiros também

12. Em 2007, é apresentado ao Congresso Nacional Brasileiro, pelo Poder Executivo, o Projeto de Lei Complementar n. 92/07, que propõe a criação das Fundações Estatais de Direito Privado para todas as áreas que não sejam exclusivas do Estado.

13. Este fórum realizou um ato público no dia 7 de abril de 2008, na Assembleia Legislativa do Rio de Janeiro (Alerj), congregando seiscentos participantes e diversas forças políticas, ou seja, dirigentes e militantes de diversos sindicatos e conselhos profissionais da área da saúde (assistentes sociais, enfermeiros, 
são criados fóruns populares de saúde, com destaque para: Alagoas, Paraíba, São Paulo e Rio Grande do Sul. A proposta de fundações já foi aprovada em mais quatro estados: Bahia, Sergipe, Pernambuco e Tocantins.

Granemann (2008) considera que as fundações estatais são um projeto de estado do capital e afirma que são formas atualizadas das parcerias público-privadas, das organizações sociais (OS) e das organizações da sociedade civil de interesse público (Oscips). A autora apresenta três questões centrais com relação à proposta. As fundações privatizam as políticas sociais, pois não contribuem para a formação do fundo público e terão imunidade tributária. As fundações estatais prejudicam os trabalhadores e não valorizam o controle social.

O Conselho Nacional de Saúde tem sido um sujeito importante nessa luta, realizando debates, seminários e divulgando notas públicas. A agenda do conselho para 2010 ressalta as seguintes prioridades: regulamentação da Emenda Constitucional n. 29; criação da carreira única da saúde; estabelecimento do serviço civil em saúde; prover a autonomia administrativa e financeira dos serviços do SUS; profissionalizar a administração e a gestão do SUS; flexibilização da lei de responsabilidade fiscal; aprovação da lei de responsabilidade sanitária; estruturação da atenção primária.

A partir de 2009 surge novamente a proposta de organização social (OS) e organização da sociedade civil de interesse público (Oscip) em vários estados brasileiros e são aprovadas em alguns, como o Rio de Janeiro.

Uma questão que se coloca é por que foi abandonada a proposta de fundação e volta-se novamente para as OS e Oscip?

Rezende (2008) considera que tanto as organizações sociais, as organizações da sociedade civil de interesse público e as fundações de direito privado são formas de transferência de responsabilidade do estado com relação à saúde para o setor privado e não se coadunam com o modelo de gestão do SUS definido constitucionalmente. A autora faz uma comparação entre o Sistema Único de Saúde e as OS e Oscip que pode ser visualizada no quadro a seguir.

\footnotetext{
nutricionistas, odontólogos, fonoaudiólogos e médicos); centrais sindicais (Conlutas e CTB); estudantes e servidores de hospitais universitários e outras unidades de saúde; militantes de movimentos populares, como as Federações de Associações de Moradores (Famerj, Faferj e FAM-Rio), além de movimentos em luta pela terra e por moradia; militantes dos partidos políticos que se posicionaram e/ou votaram contra as fundações privadas (PSOL, PSTU, PCB, PCdoB, PDT e PPS).
} 


\section{QUADRO 1 Síntese do modelo de gestão do SUS, das OS e das Oscip}

\begin{tabular}{|c|c|c|}
\hline Sistema Único de Saúde (SUS) & Organização Social (OS) & $\begin{array}{l}\text { Organização da Sociedade Civil } \\
\text { de Interesse Público (Oscip) }\end{array}$ \\
\hline $\begin{array}{l}\text { Gestão única do sistema de saúde } \\
\text { em cada esfera de governo (Gestão } \\
\text { do sistema e da rede de ações e } \\
\text { serviços). }\end{array}$ & $\begin{array}{l}\text { Autonomia administrativa e } \\
\text { financeira de cada OS. }\end{array}$ & $\begin{array}{l}\text { Autonomia administrativa e finan- } \\
\text { ceira de cada Oscip. }\end{array}$ \\
\hline $\begin{array}{l}\text { Descentralização da gestão entre } \\
\text { as três esferas de governo. }\end{array}$ & $\begin{array}{l}\text { Descentralização das ações e } \\
\text { serviços de saúde para a inicia- } \\
\text { tiva privada e não para os mu- } \\
\text { nicípios. }\end{array}$ & $\begin{array}{l}\text { Descentralização das ações e servi- } \\
\text { ços de saúde para a iniciativa priva- } \\
\text { da e não para os municípios. }\end{array}$ \\
\hline $\begin{array}{l}\text { Hierarquização dos serviços, con- } \\
\text { forme a complexidade da atenção } \\
\text { à saúde, sob comando único. }\end{array}$ & $\begin{array}{l}\text { Autonomia gerencial dos ser- } \\
\text { viços de cada OS. }\end{array}$ & $\begin{array}{l}\text { Autonomia gerencial dos serviços de } \\
\text { cada Oscip. }\end{array}$ \\
\hline $\begin{array}{l}\text { Financiamento solidário entre as } \\
\text { três esferas de governo, conforme } \\
\text { o tamanho da população, suas } \\
\text { necessidades epidemiológicas e a } \\
\text { organização das ações e serviços. }\end{array}$ & $\begin{array}{l}\text { Financiamento definido no or- } \\
\text { çamento público, para cada OS, } \\
\text { conforme a influência política } \\
\text { de seus dirigentes, com "con- } \\
\text { trapartida da entidade" por } \\
\text { meio da venda de serviços e } \\
\text { doações da comunidade e com } \\
\text { reserva de vagas para o setor } \\
\text { privado, lucrativo. }\end{array}$ & $\begin{array}{l}\text { Financiamento definido no orçamen- } \\
\text { to público, para cada Oscip, confor- } \\
\text { me a influência política de seus di- } \\
\text { rigentes, com "contrapartida da } \\
\text { entidade" por meio da venda de } \\
\text { serviços e doações da comunidade e } \\
\text { com reserva de vagas para o setor } \\
\text { privado, lucrativo. }\end{array}$ \\
\hline Regionalização. & $\begin{array}{l}\text { Inexistente, porque a entidade } \\
\text { possui autonomia para aceitar } \\
\text { ou não a oferta regional de } \\
\text { serviços, já que seu orçamento } \\
\text { é estabelecido por uma das } \\
\text { esferas de governo. }\end{array}$ & $\begin{array}{l}\text { Inexistente, porque a entidade possui } \\
\text { autonomia para aceitar ou não a } \\
\text { oferta regional de serviços, já que } \\
\text { seu orçamento é estabelecido por } \\
\text { uma das esferas de governo. }\end{array}$ \\
\hline $\begin{array}{l}\text { Universalidade e integralidade da } \\
\text { atenção à saúde. }\end{array}$ & $\begin{array}{l}\text { Focalização do Estado no aten- } \\
\text { dimento das demandas sociais } \\
\text { básicas, conforme o interesse } \\
\text { da OS. }\end{array}$ & $\begin{array}{l}\text { Focalização do Estado no atendi- } \\
\text { mento das demandas sociais básicas, } \\
\text { conforme o interesse da Oscip. }\end{array}$ \\
\hline $\begin{array}{l}\text { Participação da comunidade, com } \\
\text { a política de saúde definida em } \\
\text { conferências de saúde. }\end{array}$ & Inexistente. & Inexistente. \\
\hline $\begin{array}{l}\text { Controle social, com conselhos de } \\
\text { saúde que acompanham e fiscali- } \\
\text { zam a implementação da política } \\
\text { de saúde e a utilização de seus } \\
\text { recursos. }\end{array}$ & $\begin{array}{l}\text { Inexistente. O controle social } \\
\text { tal como previsto na Lei n. } \\
8.142 / 90 \text { é substituído pelos } \\
\text { tradicionais conselhos de admi- } \\
\text { nistração internos da entidade, } \\
\text { com paridade diferente daquela } \\
\text { estabelecida na Lei n. } 8.142 / 90 \text {, } \\
\text { e não é deliberativo. }\end{array}$ & $\begin{array}{l}\text { Inexistente. Somente a celebração } \\
\text { do termo de parceria é precedida de } \\
\text { consulta (?) aos conselhos de políti- } \\
\text { cas públicas existentes, das áreas } \\
\text { correspondentes de atuação. }\end{array}$ \\
\hline
\end{tabular}

Fonte: Rezende (2008). 
A partir do exposto, constata-se que Portugal e Brasil estão vivendo os mesmos impasses com relação à política de saúde, e considera-se fundamental a mobilização e a participação popular para enfrentar a questão, bem como o resgate da relação saúde, democracia e socialismo apontada pela Reforma Sanitária brasileira.

\section{Algumas reflexões}

O texto sinaliza que tanto Brasil como Portugal garantem de forma tardia o direito à saúde, resultante do processo de redemocratização vivenciado por ambos os países. Portugal conseguiu a universalidade da saúde após a Revolução dos Cravos, na Constituição democrática de 1976, que institui o Sistema Nacional de Saúde. No Brasil, esta conquista é resultante da Constituição Cidadã de 1988, que se consolida no Sistema Único de Saúde com as Leis Orgânicas da Saúde de 1990.

Destaca-se também que, em ambos as nações, as contrarreformas iniciam-se a partir dos anos 1990, as quais buscam a retirada de direitos sociais e a privatização das políticas sociais, com destaque para a saúde.

Brasil e Portugal estão vivenciando atualmente os mesmos impasses originários da retração do Estado e das influências do neoliberalismo acentuadas pela mundialização do capital. Como exemplos importantes na saúde devem-se apontar o desfinanciamento do setor público e a entrega da gestão dos serviços ao setor privado.

Identifica-se também, nos dois países, uma reação a essas medidas resultante dos movimentos sociais e partidos políticos de oposição. Em Portugal, as manifestações têm tido maior repercussão na imprensa e têm sido mais amplas. No Brasil, os movimentos, decepcionados com os rumos do governo Lula, se ampliaram a partir de 2007.

Como desafios para ambos os países ressaltam-se a importância da ampliação da mobilização e a organização dos movimentos sociais, bem como a valorização da consciência sanitária ${ }^{14}$ para o aprofundamento da democracia nas esferas da economia, da política e da cultura, a fim de resistir à crise estrutural do capitalismo

14. Conceito utilizado por Giovanni Berlinguer (1987), que amplia o grau de educação da população sobre saúde e seus determinantes, mas também o nível de ação coletiva voltada para a mudança de seus determinantes estruturais. 
com um movimento contra-hegemônico para superar a barbárie social da sociedade burguesa e caminhar para uma nova ordem social, antiliberal e anticapitalista.

Artigo recebido em fev./2010 - Aprovado em mar./2010

\section{Referências bibliográficas}

ABREU, S. G. Guia para acompanhamento das aulas da disciplina de Políticas Sistemas de Saúde. Coimbra: ISMT, 2004. (Mimeo.)

ABRUCIO, F. L. Os avanços e dilema do modelo pós-burocrático: a reforma da administração pública à luz da experiência internacional. In: PEREIRA, L. C. B.; SPINK, P. (Org.). Reforma do Estado e administração pública gerencial. Rio de Janeiro: Editora Fundação Getúlio Vargas, 1998.

ALMEIDA, C. M. de. Novos modelos de atenção à saúde. Bases conceituais e experiências de mudanças. In: COSTA, Nilson Rosário; RIBEIRO, José Mendes (Org.). Política de saúde e inovação institucional: uma agenda para os anos 90. Rio de Janeiro: Ensp/Fiocruz, 1996.

ARNAUT, A. História do Serviço Nacional de Saúde. Estudos do século XX, Coimbra, n. 5, 2005.

BERLINGUER, G. Medicina e política. Tradução de Pe. Bruno Giuliani. 3. ed. São Paulo: Hucitec, 1987.

BRAVO, M. I. S. Serviço Social e Reforma Sanitária: lutas sociais e práticas profissionais. São Paulo: Cortez/UFRJ, 1996.

Serviço Social e saúde: desafios atuais. Temporalis, Revista da Associação Brasileira de Ensino e Pesquisa em Serviço Social - ABEPSS/Política de Saúde e Serviço Social: Impasses e Desafios, São Luís, n. 13, ano VII, jan.-jun. 2007.

; MENEZES, J. S. B. Política de saúde no governo Lula. In: BRAVO, Maria Inês Souza et al. (Org.). Política de saúde na atual conjuntura: modelos de gestão e agenda para a saúde. 2. ed. Rio de Janeiro: Rede Sirius/Adufrj-Ssind, 2008.

BRAZ, M. O governo Lula e o Projeto Ético-Político do Serviço Social. Serviço Social \& Sociedade, São Paulo, n. 78, 2004.

CARREIRA, H. M. O Estado e a saúde. Lisboa: Público, 1996. (Cadernos do Público.) 
CHESNAIS, F. A mundialização do capital. Tradução de Silvana Finzi Foá. São Paulo: Xamã, 1996.

CUNHAL, A. $O$ aborto: causas e soluções. Tese apresentada em 1940 para exame no $5^{\circ}$ ano jurídico da Faculdade de Direito de Lisboa. 2. ed. Porto: Campo das Letras, 1997.

DINIZ, E. Crise, governabilidade e reforma do Estado. Rio de Janeiro: Editora Fundação Getúlio Vargas, 1997.

FIORI, J. L. Em busca do dissenso perdido. Rio de Janeiro: Insight Editorial, 1995.

. Ajuste, transição e governabilidade: o enigma brasileiro. In: TAVARES, M. C.; FIORI, J. L. (Org.). (Des)ajuste global e modernização conservadora. Rio de Janeiro: Paz e Terra, 1993.

GRANEMANN, S. Fundações estatais: projeto de estado do capital. In: BRAVO, Maria Inês Souza et al. (Org.). Política de saúde na atual conjuntura: modelos de gestão e agenda para a saúde. 2. ed. Rio de Janeiro: Rede Sirius/Adufrj-SSind, 2008.

HAGGARD, S. A reforma do Estado na América Latina. In: LANGONI, Carlos G. (Org.). A nova América Latina. Rio de Janeiro: Editora Fundação Getúlio Vargas, 1997.

HARVEY, D. Condição pós-moderna. São Paulo: Loyola, 1993.

KAUFMAN, R. The politics of state reform: a review of the theorethical approaches, 1995. 33 p. (Mimeo.)

KETTL, D. The global revolution: reforming government sector management. Trabalho apresentado no seminário internacional "A reforma do Estado na América Latina e Caribe - rumo a uma administração pública gerencial”. Ministério da Administração Federal e Reforma do Estado - Mare, patrocinado pelo BID e pela ONU. Brasília, 1996, p. 16-17. (Mimeo.)

MACEDO, M. E.; ALVES, A. M. Reforma administrativa: o caso do Reino Unido. Revista do Serviço Público, ano 48, n. 3, p. 63-82, 1997.

MACHADO, C. V. Contexto, atores, instituições: um estudo exploratório acerca das novas modalidades de gerência nos hospitais públicos do município do Rio de Janeiro nos anos 90. 1999. Dissertação (Mestrado) — Instituto de Medicina Social/Universidade do Estado do Rio de Janeiro, Rio de Janeiro.

MATOS, M. C. Cotidiano, ética e saúde: o Serviço Social frente à contrarreforma do Estado e à criminalização do aborto. 2009. Tese (Doutorado em Serviço Social) Pontifícia Universidade Católica de São Paulo (PUC/SP), São Paulo. 
MATTOS, R. The good governance: a nova aposta do Banco Mundial. Rio de Janeiro: IMS/Uerj, 1996. (Mimeo.)

MELO, M. A. B. C. Ingovernabilidade: desagregando o argumento. In: VALADARES, L.; COELHO, M. P. (Org.). Governabilidade e pobreza no Brasil. Rio de Janeiro: Civilização Brasileira, 1995.

NETTO, J. P. Crise do socialismo e ofensiva neoliberal. São Paulo: Cortez, 1993.

PAIM, J. Reforma sanitária brasileira: contribuições para a compreensão e crítica. Salvador: EDUFBA; Rio de Janeiro: Fiocruz, 2008.

REZENDE, C. A. P. O modelo de gestão do SUS e as ameaças do projeto neoliberal. In: BRAVO, Maria Inês Souza et al. (Org.). Política de saúde na atual conjuntura: modelos de gestão e agenda para a saúde. 2. ed. Rio de Janeiro: Rede Sirius/Adufrj-SSind, 2008 .

ROSA, E. Uma nova política econômica ao serviço das pessoas e de Portugal. Lisboa: Caminho, 2006.

SIMÕES, J. Retrato político da saúde - dependência do percurso e inovações em saúde: da ideologia ao desempenho. Coimbra: Almedina, 2004.

TEIXEIRA, S. F. Reflexões teóricas sobre democracia e reforma sanitária. In:

(Org.). Reforma sanitária em busca de uma teoria. São Paulo: Cortez, 1989. 